\title{
Vanishing white matter leukodystrophy, a rare case report
}

\section{To the Editor}

Vanishing white matter (VWM) leukoencephalopathy is an autosomal recessive disease which is also known as "childhood ataxia with central nervous system hypomyelinization". It was defined by Van der Knaap et al. (1) in 1977 for the first time. The most common type is manifested by cerebellar ataxia, spasticity and mental regression in the early childhood (2). It is known that stress is a significant factor in the disease onset and clinical exacerbations (3). The mutation which causes the disease involves the mutations in the five genes (EIF2B1,EIF2B2,EIF2B3,EIF2B4,EIF2B5) coding elF2B which is the eukariotic translation initiation factor. In time, it has been recognized that this disease which was initially described for the chidlhood and which has a wide range of phenotypic variability can affect patients at any age $(1,4)$. We wanted to present this patient because he was the first genetically proved case in Turkey and we wished to emphasize that this rare disease should be considered in the differential diagnosis of neurodegenerative diseases in the childhood.

Our patient who was a 8-year-old male patient presented because of gradually increasing loss of motor abilities following an upper respiratory tract infection with fevet at the age of four for the first time. The family who recognized his muscle weakness observed that the child had unsteady gait and that this increased in time. His medical history revealed that his perinatal history and neurological development until the age of one were normal. The mother and father were third degree relatives and familial history was found to be normal.

On physical examination, the height and weight were found to be normal, visual and auditory problems were absent and cognitive functions were compatible with his age. Our patient had no dysmorphic charactersitic. Ataxia, intentional tremor in both upper extremities and dysdiyadochinesia were found on neurological examination. Diffuse hypotonia and decrease in muscle strenght in all extremities were found. Muscle strength was found to be $4 / 5$ in the left arm, right arm and left leg and $3 / 5$ in the right leg. Both Achilles reflexes and patella reflexes were found to be increased. Clonus and Babinsky were found to be positive in both lower extremities. Fundoscopic examination was found to be normal. Examination of the other systems was found to be normal. Regular screenings and metabolic tests were found to be normal in the laboratory findings. On magnetic resonance imaging (MRI) of the brain, diffusely increased density in the white matter in FLAIR sequences and locally cystic areas with the same intensity as the cerebrospinal fluid were observed .

VWM disease was considered with the clinical findings and brain MR findings in the patient in whom genetic analysis was planned. Genetic mutation analysis revealed homozygous mutation in the EIF2B5: $943 \mathrm{C}>\mathrm{G}$ (DNA)/R315G (protein) gene. The mother and father were found to be carriers for the same mutation. Thus the diagnosis of VWM disease was confirmed.

Our patient is now receiving physiotherapy and individual education in a special education center. Worsening in the acute motor functions was observed for two times in 2010 and 2011. Our patient had fever during both of these worsening attacks. In the follow-up, the intellectual functions were found to be retarded for his age. No auditory or visual problem developed. The patient who had an articulation problem while speaking did never lost comprehensibility in the communication with the people around. The patient whose muscle weakness increased is not able to perform daily activities by himself for the time being.

The disease is manifested by cerebellar ataxia and more rarely with spasticity. The consciousness is usually preserved. In the advanced period, vision loss with optic atrophy is among the findings described (1). Vermeulen et al.(3) emphasized that stress was an important factor both in the onset of the disease and clinical exacerbations. Other factors which speed the progression include infections with fever, cranial traumas and fear spells. Outside these periods, the disease has a slow clinical course, but mortality is inevitable $(2,3)$. It was learned that our patient had an upper respiratory tract infection with fever at the time the first symptoms appeared.

Address for Correspondence: Serhat Güler MD, Bezmialem Foundation University Medical Faculty, Division of Pediatric Neurology, İstanbul, Turkey

E-mail: serhatguler@hotmail.com Received: 06.30.2012 Accepted: 11.15.2012

Turkish Archives of Pediatrics, published by Galenos Publishing 


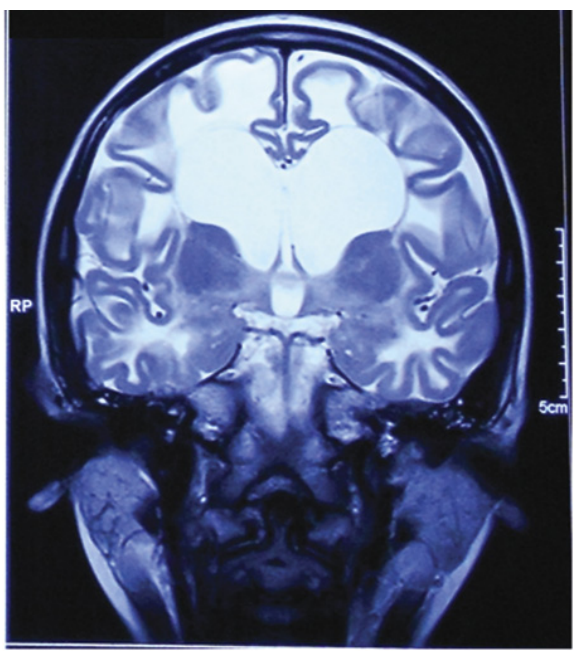

Figure 1. Diffuse hyperintensity in the white matter, locally cystic areas with the same intensity as the cerebrospinal fluid in the FLAIR sequences

In the early childhood, brain MRI is the most strong supporting tool for the diagnosis. On MRI, progressive decrease in volume and cystic degeneration are observed in the white matter. MR spectroscopy reveals progressive decrease in all metabolites which can be tested. Cerebellar and brain stem involvement is observed in the lost white matter. In the later stages, cerebral and cerebellar atrophy is observed $(1,2)$. Cortical grey matter is always preserved (1). On cranial MRI of our patient, enlargement in the lateral ventricles (Figure 1) and cerebellar atrophy in the T2-weighted sections, diffusely increased intensity in the white matter and cystic areas with the same intensity as the cerebrospinal fluid in FLAIR sequences were observed.

For the time being, there is no treatment for the disease except for supportive treatment which is given to increase the quality of life.

In time, it has been recognized that this disease which was initially described for the chidlhood and which has a wide range of phenotypic variability can affect patients at any age $(1,5)$. In the prenatal form of the disease, decreased fetal movements, oligohydramniosis, primary microcephaly, growth retardation, congenital contractures, renal hypoplasia, hepato- splenomegaly, pancreatitis, cataract, ovarian dysgenesis and leukoencephalopathy may be observed (6).

Conclusively, vanishing white matter disease is a rare genetic disease. In the diagnosis, a history of discontinuation and regression of motor functions which start in the childhood, progressive ataxia, spasticity and intermittent worsening attacks is important. Mutation analysis which is performed as a result of the findings observed on cranial MR confirms the diagnosis. Early diagnosis is very important in terms of genetic counseling and protecting the patient from the factors which worsen the disease. Researches for the unknown molecular mechanisms of this disease which has a wide clinical spectrum are continuing. We wanted this patient who was the first genetically confirmed case in our country to remind physicans to consider this disease in the differential diagnosis in patients presenting with motor retardation.

Serhat Güler, Adnan Yüksel, Akın Işcan, IIhan Ișık, Burak Tatlı Bezmialem Foundation University Medical Faculty, Division of Pediatric Neurology, Istanbul, Turkey

\section{References}

1. Bugiani M, Boor I, Powers JM, Scheper GC, van der Knaap MS. Leukoencephalopathy with vanishing white matter: a review. J Neuropathol Exp Neurol 2010; 69(10): 987-986.

2. van der Knaap MS, Kamphorst W, Barth PG, Kraaijeveld CL, Gut E, Valk J. Phenotypicvariation in leukoencephalopathy with vanishing white matter . Neurology 1998; 51: 540-547.

3. Vermeulen G, Seidl R, Mercimek-Mahmutoglu S, Rotteveel JJ, Scheper GC, van der Knaap MS. Fright is a provoking factor in vanishing white matter disease. Ann Neurol 2005; 57(4): 560-563.

4. van der Knaap MS, Leegwater PA, Könst AA, Visser A, Naidu S, Oudejans CB, Schutgens RB, Pronk JC. Mutations in each of the five subunits of translation initiation factor elF2B can cause leukoencephalopathy with vanishing white matter. Ann Neurol 2002; 51(2): 264-270.

5. van der Knaap MS, Leegwater PA, van Berkel CG, Brenner C, Storey E, Di Rocco M, Salvi F, Pronk JC. Arg113His mutation in elF2Bepsilon as cause of leukoencephalopathy in adults. Neurology 2004; 62(9): 1598-600.

6. van der Knaap MS, van Berkel CG, Herms J, van Coster R, Baethmann M, Naidu S, Boltshauser E, Willemsen MA, Plecko B, Hoffmann GF, Proud CG, Scheper GC, Pronk JC. elF2B-related disorders: antenatal onset and involvement of multiple organs. Am J Hum Genet 2003; 73: 1199-207. 